\title{
O desafio de levar filmes africanos ao público africano
}

Emi Koide ${ }^{1}$

Festival Lagunimages (Cotonou, Benim) - 5 a 8 de dezembro de 2013.

O Festival Lagunimages foi criado em 2000 em Cotonou pela cineasta belgo-congolesa Monique Mbeka Phoba. Trata-se de um festival bianual dedicado à difusão do cinema produzido por diretores africanos ao público em geral, destacando sobretudo a produção de documentários e séries televisivas africanas. Naquela ocasião não havia no Benim nenhum festival de cinema. A partir de 2007, Phoba e seus colaboradores criaram a Associação Lagunimages e com a partida de sua iniciadora depois da edição de 2009, a realizadora Christiane Chabi Kao e a produtora cultural Noudéou Noëlie Houngnihin, ambas beninenses, continuaram a organizar o evento.

A grande relevância desta iniciativa é o fato de responder à necessidade, ao desafio e à urgência de difundir produções audiovisuais africanas para os próprios africanos. 50 anos depois do primeiro filme realizado por Ousmane Sembène, considerado o pai do cinema africano, os filmes produzidos por realizadores do continente africano continuam em larga medida inacessíveis e pouco difundidos junto ao público local. Ou seja, o desejo de Sembène, que nos parece absolutamente emblemático e que traduz ainda hoje uma parte da situação africana, era de falar amplamente ao povo africano de sua própria realidade - que o cinema servisse ao projeto de descolonização do imaginário africano - decidindo-se dedicar ao cinema para trazer imagens africanas, em produções faladas em línguas locais como wolof ou dioula para o povo. Sembène afirmava que "a África é meu público, e o Ocidente e o resto são somente mercados" (Gadjigo). No entanto, este objetivo e anseio ainda não se realizaram plenamente. Ironicamente como indicam Watson e Gadjigo $^{2}$ continua a ser difícil ver os filmes clássicos de Sembène na

\footnotetext{
${ }^{1}$ Universidade Federal de São Paulo, Departamento de História da Arte, Guarulhos - SP, CEP: 07112-000, Brasil.

${ }^{2}$ Watson (2007) observa justamente a ironia dos filmes de Sembène serem dificilmente acessíveis na África Ocidental, sobretudo no Senegal - onde alguns foram censurados - restrito ao meio universitário ou ainda que para ver a obra do cineasta seria necessário ir às capitais ocidentais. Gadjigo (2007), biógrafo do cineasta senegalês, embora tivesse conhecido a obra literária do artista durante sua juventude, descobre tardiamente a produção fílmica do realizador nos Estados Unidos e fica justamente intrigado pelo fato dos senegaleses - público alvo original para Sembène - desconhecerem seus filmes.
} 
África Ocidental. Seus filmes, bem como de outros realizadores, são mais facilmente encontrados na Europa ou nos Estados Unidos.

A situação não é diferente em outros países do continente africano hoje. Há o FESPACO, maior e mais importante festival do cinema africano, e tantas outras iniciativas novas surgindo no continente nos últimos anos, no entanto, pouquíssimos são os espaços para difusão do cinema africano ao grande público, que não tenha seu acesso restrito aos artistas, intelectuais e à elite local. Salvo em espaços como o Institut Français, são poucos os espaços para a exibição de filmes africanos na África francófona. No entanto, há que se observar que em Cotonou, capital econômica do Benim, o Institut Français é freqüentado por um publico limitado à pequeníssima classe média local, elite beninense e expatriados estrangeiros, de tal modo que ouvi de muitos beninenses repetidas vezes que era um lugar para "brancos" e não para a população de modo geral. Tal como observa Lelièvre (2010) muito se fala da fragilidade da produção audiovisual africana, sobretudo devido à dependência de financiamento e apoio provindos do ocidentais, principalmente franceses - no caso da África francófona - o que de fato é um problema $^{3}$, no entanto pouco se fala da distribuição e difusão dos filmes em África ${ }^{4}$. Assim, são as telenovelas brasileiras e mexicanas que são consumidas intensamente pelo público desta parte da África Ocidental, por vezes algumas produções de série televisivas locais.

O Lagunimages é singular também pelo destaque dado à produção de documentários africanos. Segundo Houngnihin, diretora da edição 2013, mesmo no plano internacional constata-se a ausência do documentário produzido em África - com exceções pontuais - e tal produção é ainda menos exibida que os demais filmes africanos. Ela afirma que, curiosamente, a maior parte dos documentários sobre as realidades africanas continuam a ser realizados por ocidentais e estes são amplamente difundidos nas próprias televisões africanas. Além disso, ela aponta também para um outro problema crucial: a ausência de fundos que financiem documentários africanos, pois estes parecem não corresponder aos

\footnotetext{
${ }^{3} \mathrm{O}$ problema da dependência de financiamentos e a limitação que isto traz à produção africana no contexto da África francófona no pós-independência, tal como apresentado por Diawara (1992), com a presença do C.A.I (Consortium Audio-visuel International) - com equipes técnicas francesas e pós-produção em Paris - parecem continuar nos dias de hoje. Tanto as organizadoras do festival, como outros profissionais do audiovisual beninenses, afirmaram que as condições para obter os fundos de apoio implicam em ter equipes técnicas francesas e roteiros pré-aprovados pela França. Achille Mbembe (2009) também apresenta as condições desiguais e de afirmação de poder ocidental no campo da cultura no continente africano através dos financiamentos que levam a reforços de estereótipos e minam a criatividade e expressão local.

${ }^{4}$ Uma das iniciativas analisadas por Lelièvre é o "Cinéma numérique ambulant" que visa projetar filmes africanos ao público que se encontra longe dos centros urbanos, em áreas desprovidas de energia elétrica e que não teriam acesso a tal produção não fosse a iniciativa de projeção itinerante.
} 
fantasmas e anseios de uma certa imagem da África que ainda subsiste no imaginário ocidental ${ }^{5}$. Deste modo, o festival cumpre também o papel de fazer com que o documentário africano chegue à platéia africana. A cidade de Cotonou não possui hoje nenhuma sala de cinema, as poucas que existiam deram lugar a igrejas pentecostais.

\section{Desafios da $7^{\mathrm{a}}$ edição -2013}

Cotonou é uma cidade viva e repleta de contrastes. Há inúmeros problemas: ausência de saneamento básico e coleta de lixo, hospitais precários e praticamente nenhuma iniciativa cultural realizada ou apoiada pelo estado. O salário mínimo médio é de aproximadamente 30.000 Francos CFA (45 euros), embora parte considerável da população viva com menos, a grande maioria em trabalhos informais. Apesar de tudo isto é uma cidade efervescente, com grandes artistas - muitos mais conhecidos do público ocidental do que beninense como Romuald Hazoumé, Georges Adéagbo, assim como muitos jovens artistas - e novos centros culturais organizados pelos próprios artistas. Em meio a tudo isto, o Lagunimages 2013, que para sua $7^{\mathrm{a}}$ edição recebeu pouquíssimo financiamento, realizou durante quatro dias projeções em praças públicas e mercados de Cotonou - Place de Martyrs, mercado de Godomey, escolas públicas. Nesta edição ainda ampliou os espaços de projeções para outras cidades mais distantes, Allada e Parakou. Equipes de voluntários, a imensa maioria jovens estudantes da Universidade Abomey Calavi, juntamente com as diretoras do festival, levavam projetores da própria associação aos locais, às vezes havia uma pequena tela, por vezes um tecido improvisado que era esticado. E as projeções ocorriam. Nos espaços públicos, muitos passantes paravam para assistir aos filmes. Para Houngnihin, dada a ausência de espaços culturais freqüentado por todos, bem como a inexistência de iniciativas de fomento no campo da cultura realizadas pelo próprio governo local, não há o hábito da população em geral de ir aos centros culturais, daí a necessidade de ir para as ruas para encontrar o grande público.

A programação continha uma seção temática - que neste ano foi dedicada às culturas urbanas; uma dedicada à produção beninense - sobretudo aos filmes produzidos por alunos e ex-alunos da ISMA (Institut Supérieur des Métiers de l'Audiovisuel) criada em 2006; uma seção de programação de filmes infantis exibidos; outra de premiados do FESPACO e a última de país convidado, que neste

\footnotetext{
${ }^{5}$ Thackway (2003) e Barlet (1997) colocam a problemática dos diretores da África francófona que ao tratar de temas urbanos e contemporâneos recebem críticas ocidentais desfavoráveis por não serem suficientemente "africanos", consequentemente enfrentam dificuldades em conseguir apoio e fundos para a realização e difusão de filmes que devem passar por um crivo de "africanidade" da imagem que o Ocidente faz do continente.
} 
ano foi o Brasil ${ }^{6}$. Grande parte da programação traz filmes já conhecidos e consagrados no contexto internacional, mas que continuam desconhecidos do grande público beninense. Não incide aqui o critério de lançamentos recentes e filmes inéditos, salvo a seção de filmes da ISMA. Dada a escassez de recursos, filmes já lançados em DVDs disponíveis via Institut Français e redes de embaixadas é uma condição para a exibição. Os filmes selecionados segundo o tema culturas urbanas traziam desde o documentário Frangafrika - La voix de sans voix (2006), de produção francesa sobre a cena do rap e hip hop no continente africano ao premiado Ouaga Saga (2004) de Dani Kouyaté. Certamente são filmes em sua maioria mais facilmente encontrados no Ocidente, sobretudo na França.

A parte da programação que mais dificilmente circularia no Ocidente é a seção "La vision intérieure", dedicada à produção beninense. Aqui a maior parte dos filmes eram curtas-metragens realizados pelos alunos da ISMA, única escola local privada de formação superior em audiovisual, em que há também muitos alunos de outros países africanos. Tratam-se de produções pautadas em linguagem televisiva, sobretudo em telenovelas e seriados, fortemente calcadas no melodrama e com apelo popular. Dois filmes que se passam no espaço urbano, Le prix a payer (2012) do estudante togolês Maxime Tchinckoun e Rencontres virtuelles (2012) do estudante beninense Ayéman Aymar Esse, receberam prêmios em festivais africanos, sobretudo o último, que foi agraciado com o grande prêmio Kodjo Eboucle no Festival Clap Ivoire 2012 (Costa do Marfim), e ainda recebeu dois prêmios no FESPACO 2013: prêmio do júri de filmes produzidos em escolas africanas e prêmio especial de direitos humanos e civismo. Rencontres virtuelles traz uma estória urbana de uma paquera virtual de uma jovem com um homem mais velho que trocam mensagens pelo internet, mas a história acaba mal, com uma gravidez indesejada e um aborto mal sucedido. No entanto, o filme é, a meu ver, extremamente moralista, simplista e conservador. Curiosamente o mesmo tema do aborto é tratado no outro filme, Le prix a payer, que também foi premiado no Clap Ivoire como melhor ficção, em que pesa a mesma condenação moral contra o aborto e a protagonista feminina sob fortes tintas melodramáticas. Outros curtas de ficção também tratavam de temas sociais, e estes falados em língua local fongbe: Juste un regard (2012) de Olivier Zinsou em que se acompanha o drama de crianças abandonadas em busca da mãe que saiu de casa em busca do marido; Doudedji (2012) de Evelyne Hessou traz a estória de um menino deficiente que não pode andar e que enfrenta os pais e o preconceito para poder ir à escola. Todos estes curtas trazem claramente uma mensagem moral, com reafirmações do ponto de vista do senso comum. Do ponto de vista da linguagem também parece não haver espaço para ousadia e criatividade, reproduzindo modelos da telenovela e muitos

\footnotetext{
${ }^{6}$ Sobre a programação de filmes brasileiros ver http://ficine.org/?p=645
} 
preocupados em alcançar padrões técnicos da grande mídia globalizada. De todo modo, são produções que falam de temas locais que têm potencial espaço nos canais televisivos locais e assim maior possibilidade de exibição.

Ao logo dos anos, o festival tem cumprindo um papel educativo também ao oferecer oficinas de formação para realizadores desde sua criação e a partir da edição 2013 realiza um trabalho de mediação cultural e formação junto ao público infantil, o projeto piloto ocorreu na escola pública Océan. Crianças tiveram oficinas para realizar curtas-metragens que foram exibidos na abertura do festival. Houve também projeções de filmes para o público infanto-juvenil na escola. A ideia é que a iniciativa se expanda para outras escolas. Para as organizadoras, esta mediação cultural e iniciação ao audiovisual são essenciais também como forma de exigir do governo que as artes sejam incluídas no currículo escolar desde a infância. Segundo elas, após o fim da ditadura de Kérékou e o advento do pluripartidarismo de das eleições a partir de 1990, houve a exclusão da educação artística da escola, que seria um dos motivos para a não formação de um público que pouco consome cultura. Assim, elas pensam que a sensibilização com crianças em escolas permite preencher uma lacuna que existe no sistema educacional e exigir o retorno das práticas de artes às escolas. Também ocorreu um atelier prático de formação em documentário para televisão ministrado pelo realizador suíço Felix Karrer aos alunos da ISMA. O resultado final foi uma dezena de curtas sobre diversos temas beninenses que foram exibidos próximo ao final do evento. Destes saíram muitas produções interessantes - mais ricas, ao meu ver, que os premiados curtas de ficção da ISMA - que certamente mereceriam mais projeções no decorrer do festival, como um documentário sobre o cotidiano do trabalho dos zemidjans (taxi-motos) e outro sobre o problema do lixo em Cotonou. Mas, sem dúvida, a principal importância deste festival é certamente realizar, em certa medida, ainda que a cada dois anos, durante alguns dias, o desafio de levar filmes africanos ao seu público. Deste modo, cumpre uma parte importante do legado não realizado de Sembène - embora a ideia de descolonização tenha tomado outro sentido, dado que os filmes trazem elementos da realidade local, mas sem o ideal emancipatório e político dos anos $60-\mathrm{e}$ faz com que finalmente o áudio-visual africano encontre o povo nas ruas.

\section{BIBLIOGRAFIA}

Barlet, Olivier. 1997. "La critique occidentale des images d'Afrique". Africultures, n.1, octobre: 5-11. 
Diawara, Manthia. 1992. African cinema: politics and culture. Indiana: Indiana University Press.

Gadjigo, Samba. "Ousmane Sembène: The Life of a revolutionary artist."

http://www.newsreel.org/articles/ousmanesembene.htm

Gadjigo, Samba. 2007. "Ousmane Sembene: la lutte continue! A pernoal tribute”. Research in African Literatures, vol. 38, n.4 (Winter): 1-3.

Lelièvre, Samuel. 2010. "Diffuser les films africains en Afrique". Études Océans Indiens, 44: 227-241.

Mbembe, Achille. 2009. "Art contemporain d'Afrique: négocier les conditions de la reconnaissance”. Africultures, 2 décembre. http://www.africultures.com/php/index.php?nav=article\&no $=9028$

Thackway, Melissa. 2003. Africa shoots back - alternative perspectives in Sub-Saharan Francophone African films. Oxford, Indiana: Indiana University Press.

Watson, Julia. 2007. "Ousmane Sembene: a memorial tribute". Research in African Literatures, vol. 38, n.4 (Winter): 4-6. 